\title{
Presentación
}

Continuando ininterrumpidamente con la tarea iniciada en 1995, nuestra revista persiste en la misión de contribuir a la investigación y reflexión acerca de las problemáticas y situaciones sociales, y al análisis de los modos de intervención social que surgen como respuesta desde diversos actores sociales. Lo anterior, hoy se manifiesta en un contexto de creciente diversidad de la población y acentuada desigualdad social, y exige dar cabida al examen de nuevas estrategias de intervención social y a la resignificación de los enfoques teóricos que orientan estos procesos de transformación.

En este sentido, el presente número de la Revista Perspectivas invita a sus lectores a revisar un conjunto de diversos trabajos, resultado del esfuerzo de académicos y profesionales de diversas disciplinas de las ciencias sociales, provenientes de diversas latitudes e instituciones. Los artículos que se presentan dan cuenta de los complejos cambios que hoy experimenta la sociedad y advierten la manifestación de problemáticas que requieren del reconocimiento de nuevas subjetividades, en el marco de una sociedad en la que persiste la concentración desigual del poder y de la riqueza. Los trabajos han sido evaluados por un selecto y riguroso equipo de evaluadores de América Latina, lo cual nos permite ofrecer una propuesta seria y constructiva, para estimular la discusión teórica y recrear las intervenciones de los trabajadores sociales y otros profesionales.

Antes de presentar los artículos que dan vida al presente número, en nombre de la Dirección de nuestra revista, del Equipo Editorial, y la Escuela de Trabajo Social de la UCSH, queremos agradecer el trabajo de la Dra. Ana María Álvarez, quien fuera editora de esta publicación. Reconocemos su aporte en la proyección de la Revista Perspectivas y deseamos todo el éxito en las nuevas labores institucionales que ha asumido.

\section{Resultados de investigación}

En este apartado se encuentra en primer lugar el trabajo de Lilian Sanhueza, Javiera Saldías, Yasna Contreras y Paola Pizarro “Apoyo 
Social para la Parentalidad: experiencias en programas de infancia en Chile", resultado de una investigación llevada a cabo en la Región de La Araucanía, en la que participan hombres y mujeres provenientes de diversos contextos. Los resultados demuestran las dificultades que atraviesan principalmente las mujeres y cómo inciden en su labor parental.

En seguida se presenta la investigación de carácter cualitativo, realizada por Carolina Monsalve Reyes, $\mathrm{M}^{\mathrm{a}}$ Angélica Parada, Natali Ormeño Stuardo y Verónica Gómez: "Relaciones intergeneracionales: profesoras seniors con niños y niñas del Programa Socioeducativo Penco, Chile". Se trata de un estudio que se adentra en la valoración de las relaciones intergeneracionales en el marco de un programa socioeducativo en el sur de Chile.

A continuación, el trabajo "Creencias de padres haitianos: Rol de la escuela en la inclusión social de sus hijos/as". Esta investigación de Carla Fierro Retamal da cuenta de la diversidad cultural en los establecimientos de educación, e interpela por el reconocimiento de las creencias de los inmigrantes, en la perspectiva de una inclusión social efectiva.

Siguiendo con los trabajos que derivan de resultados de investigación, se presenta el artículo "El fútbol callejero como herramienta educativa de transformación social en la comuna de Pedro Aguirre Cerda: organización PAC Gol". Este trabajo, de Juan Ignacio Gutiérrez, es el resultado de una investigación cualitativa que considera el fútbol callejero como una metodología que, desde la perspectiva freireana, permite confrontar la reproducción de estereotipos anclados en la educación formal y en dimensiones del futbol tradicional.

\section{Análisis y reflexiones sobre la intervención social}

Al inicio de esta sección se encuentra el trabajo de Verónica Gómez y Fania Cid "Experiencia colaborativa de la Mesa Técnica contra la Explotación Sexual Comercial de la niñez en Bíobio". Las autoras dan cuenta del trabajo desarrollado por una instan- 
cia multisectorial, orientada a garantizar los derechos de los más jóvenes en materia de explotación sexual. El análisis se dirige a las causas estructurales que naturalizan esta problemática, y pone acento en la transformación de las prácticas de quienes intervienen en este ámbito.

\section{Análisis del Trabajo Social, transformaciones y desafíos}

Da comienzo a esta sección el trabajo de Karina Aedo titulado "La acción social profesional del Trabajo Social en el área de justicia juvenil en Chile". La autora ofrece un análisis de la acción profesional en el contexto de las transformaciones de las políticas públicas del sector en una sociedad de carácter neoliberal, lo cual pone en tensión la acción profesional, toda vez que este tipo de política sostiene un modelo de sociedad marcado por la injusticia y la desigualdad social.

Continuando en esta sección, la autora Estefanía Vilches presenta un artículo "VIH y políticas preventivas en Chile. La importancia de la enunciación en la intervención desde Trabajo Social". En este análisis, la autora critica las actuales políticas públicas en el sector salud, particularmente en el abordaje de la situación de quienes viven con VIH. Sostiene que es esencial la búsqueda de aquellas relaciones de poder que reducen a la sociedad, y desde allí interpela por un cambio en la noción de "intervención preventiva".

Al finalizar esta sección, la autora Johanna Camila Ramírez Mellado, en su artículo "Fundamentos de un Trabajo Social Clínico feminista: una perspectiva de género, raza e interseccionalidad", ofrece un análisis desde las recientes orientaciones para la práctica profesional en el sector salud, con el propósito de incorporar, desde una perspectiva feminista, una serie de conceptos y prácticas en el Trabajo Social Clínico. 